\title{
Corals worldwide hit by bleaching
}

\section{Warm ocean waters combine with El Niño to turn reefs a stark white.}

\section{Alexandra Witze}

08 October 2015

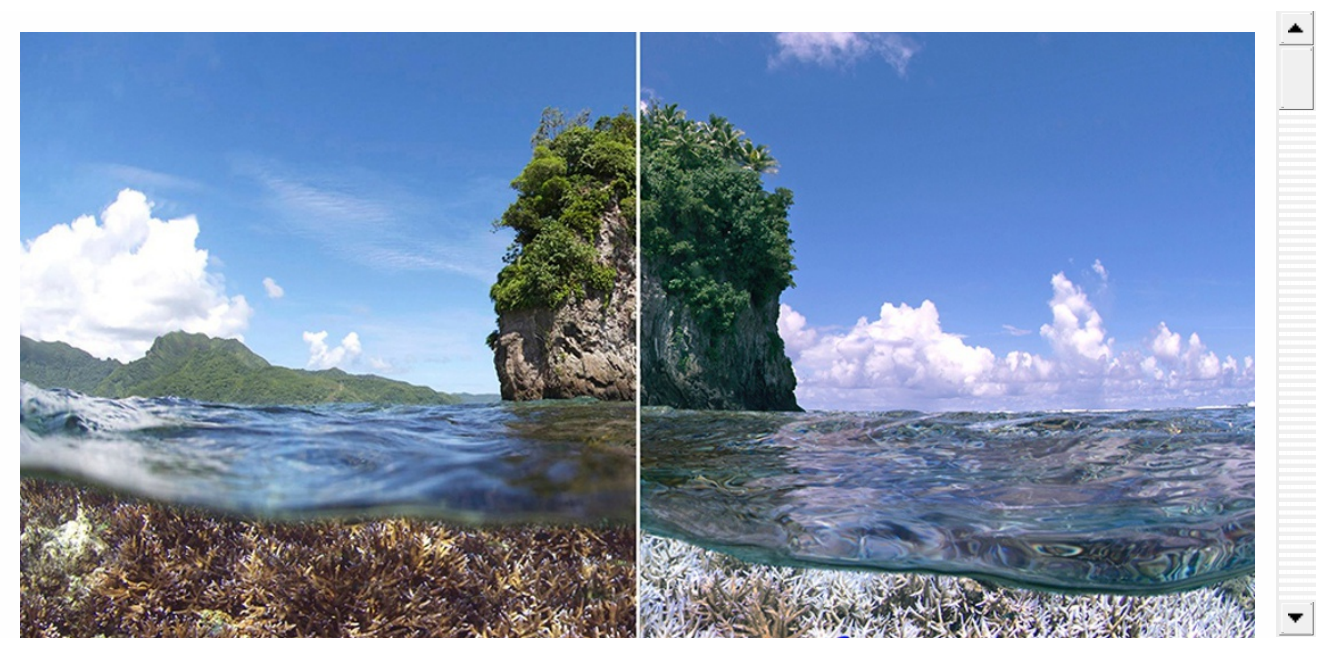

From Hawaii to Papua New Guinea to the Maldives, coral reefs are bleaching — in so many regions that the US National Oceanographic and Atmospheric Administration (NOAA) officially declared a global bleaching event on 8 October. The event, the third in recorded history, is expected to grow worse in coming months.

Warm ocean temperatures, linked to climate change and a strengthening El Niño weather pattern, have triggered reefs to expel the algae that colour them. Reefs in parts of the Pacific, the Indian and the Atlantic oceans have now turned white. By the end of the year, the bleaching could affect more than a third of the world's coral reefs and kill more than 12,000 square kilometres of them, NOAA estimates.

"We're in shock and awe of what's happening," says Ove Hoegh-Guldberg, a marine scientist at the University of Queensland in Brisbane, Australia. "It's a doozy of an event."

Bleached corals are more vulnerable to stressors such as disease that can kill them. In 1998, the biggest bleaching event in history led to the death of $16 \%$ of the world's coral reefs.

\section{Poor prognosis}

The current event began in 2014 in parts of the Pacific — including the Hawaiian Islands, which experienced mass coral bleaching around multiple islands. Global ocean temperatures last year were nearly 0.6 degrees Celsius higher than the twentieth-century average, a record high. "We came into 2015 with very warm oceans, and now we have a full-formed El Niño coming," says Mark Eakin, coordinator of NOAA's Coral Reef Watch programme, run out of Washington DC.

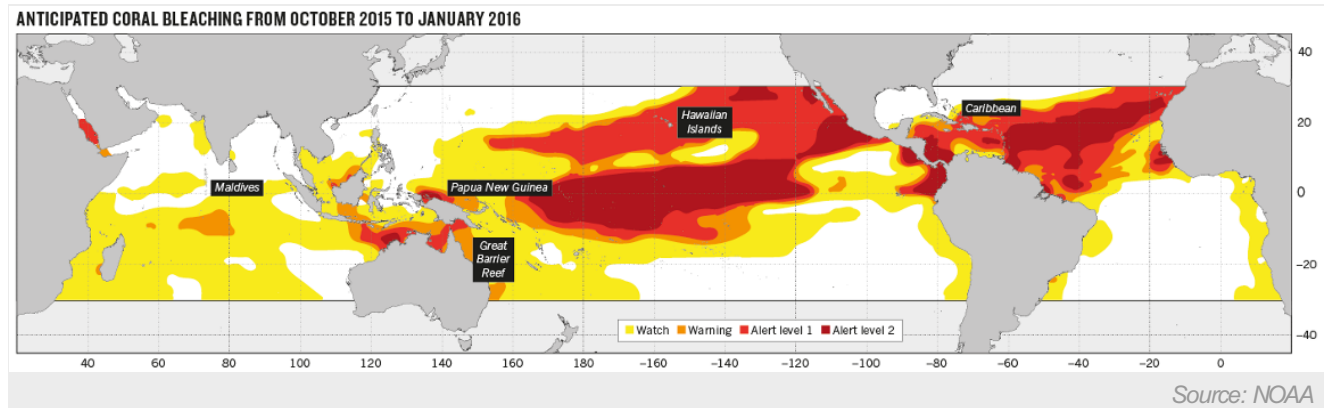

This map shows areas at highest risk of bleaching from now until January 2016. 
several months, also helping to keep temperatures high. (It is unclear whether the blob is linked to climate change or other large-scale atmospheric patterns.)

"The temperatures we're seeing are anomalies, and have the potential to dramatically impact the integrity of reefs around the world," says Ruth Gates, a marine biologist at the Hawaii Institute of Marine Biology in Kaneohe.

NOAA models suggest that by mid-2016, the bleaching will have spread even further through most of the world's coral-bearing regions, extending across nearly all of the Indian Ocean and the South Pacific.

NOAA uses data on sea-surface temperature, gathered by its Polar-orbiting Operational Environmental Satellites, to produce global maps depicting where waters are warm enough to trigger bleaching. Local marine scientists, volunteers and others - under the umbrella of monitoring groups such as Reef Check in Marina del Rey, California - then go out to inspect the conditions where bleaching may be happening.

\section{Private eyes}

A privately funded venture, the XL Catlin Seaview Survey, has been mapping reefs in 26 countries since 2012. Among other technologies, it uses a high-resolution camera attached to an underwater scooter to quickly compile 360-degree images of reefs.

This effort should help scientists to document mass bleaching during the present event better than during the last one, which happened in 2010. The Global Coral Reef Monitoring Network, an international government-based initiative, was reorganized in 2008 and shifted from gathering data on reefs to preparing reports on the basis of data from others. As a result, there was not a full network in place during 2010 to monitor coral status, Eakin says. "We're not going to let this one slip by," he adds.

Marine scientists need to document long-term changes to corals in many regions to understand how reefs might survive bleachings, says Gates. In a bay off the island of Oahu in Hawaii, some corals that experienced bleaching in 2014 surprisingly managed to reproduce this year, even with back-to-back bleachings. And earlier this year, a Nature paper ${ }^{1}$ reported that 12 out of 21 reefs studied in the Seychelles managed to mostly recover after the devastating bleaching of 1998.

But Hoegh-Guldberg notes that bleaching events may now be coming too quickly, giving corals no time to recover between them. "Reefs, like rainforests, take time," he says. And other factors, such as ocean acidification, are also stressing corals to the point that decades from now, reef communities will look and function much differently than they do today, says Cheryl Logan, a marine biologist at California State University, Monterey Bay, in Seaside.

Nature | doi:10.1038/nature.2015.18527

\section{References}

1. Graham, N. A. J., Jennings, S., MacNeil, M. A., Mouillot, D. \& Wilson, S. K. Nature 518, 94-97 (2015). 